\title{
Ferromagnetic shape memory alloys: structural and thermal properties
}

\author{
J.J. Suñol ${ }^{11}{ }^{1}$ L. Escoda ${ }^{1}$, R. Coll ${ }^{1}$, J. Saurina ${ }^{1}$, T. Sánchez, V.M. Prida, B. \\ Hernando ${ }^{2}$ \\ ${ }^{1}$ Universidad de Girona, Campus Montilivi, Lluís Santaló s/n, 17003 Girona, Spain \\ ${ }^{2}$ Dept.de Física, Universidad de Oviedo, Calvo Sotelo s/n, 33007 Oviedo, Spain \\ E-mail: joanjosep.sunyol@udg.edu
}

\begin{abstract}
The most extensively studied Heusler alloys are those based on the Ni-Mn-Ga system. However, to overcome the high cost of Gallium and the usually low martensitic transformation temperature, the search for Ga-free alloys has been recently attempted, particularly, by introducing In, Sn or Sb. In this work, two alloys (Mn50Ni35.5In14.5 and Ni50Mn35In15) have been obtained by melt spinning. We outline their structural and thermal behaviour. Mn50Ni35.5In14.5 alloy has the transformation above room temperature whereas Ni50Mn35In15 does not have this transformation in the temperature range here analyzed.
\end{abstract}

\section{Introduction}

Ferromagnetic alloys with shape memory exhibit both ferromagnetic and shape memory effect simultaneously. The ferromagnetic shape memory effect can be controlled by temperature and stress, as well as by magnetic field. These alloys exhibit a first-order austenite-martensite phase transition. It is a cyclic process. By lowering the temperature a cubic high-temperature parent austenite phase transforms into a tetragonal, orthorhombic or monoclinic structurally modulated martensite ordered by domains. By heating from the martensite state the materials transforms into austenite. The transition temperatures of shape memory alloys strongly depend on the composition and their values spread in a very wide range. Their potential functional properties are: magnetic superelasticity, large inverse magnetocaloric effect and large magneto-resistance change [1-4]. These properties make them of noteworthy interest for developing new stress, thermal and/or magnetically driven actuators, sensors and magnetic coolants for magnetic refrigeration.

$\mathrm{Ni}-\mathrm{Mn}-\mathrm{Sn}$ and Ni-Mn-In systems are of prospective importance as ferromagnetic shape memory alloy. In the last decade, these alloys were produced as bulk polycrystalline ingots by arc melting followed by high temperature homogenization annealing. Nowadays, ferromagnetic $\mathrm{Ni}_{50} \mathrm{Mn}_{50-\mathrm{y}} \mathrm{X}_{\mathrm{y}}$ alloys with $\mathrm{X}=\mathrm{Sn}$, and $\mathrm{In}$, can be directly produced as single phase microcrystalline materials by rapid solidification using melt spinning technique [5-7]. Austenite crystallizes usually into a cubic $L 2_{1}$-type structure that with the lowering in temperature transforms into a modulated martensite with orthorhombic or monoclinic structure for Sn and In systems, respectively. Present contribution

1 To whom any correspondence should be addressed. 
is devoted to outline the structural and thermal properties of melt spun small flakes of two selected compositions in the In system.

\section{Materials and methods}

As-cast pellets of nominal composition $\mathrm{Ni}_{50} \mathrm{Mn}_{50-\mathrm{x}} \mathrm{In}_{\mathrm{x}}(\mathrm{x}=14.5$ and 15) were prepared by $\mathrm{Ar}$ arc melting from $99.98 \%$ pure Ni, $99.98 \%$ \% pure Mn, and $99.999 \%$ pure In, using Bühler MAM-1 compact arc melter. Ingots were melted four times to ensure a good starting homogeneity. Annealing at $1273 \mathrm{~K}$ was performed in order to obtain more homogeneous alloys. The samples were melt-spun in argon environment. In this work, we select small flakes.

The austenite-martensite structural transformation was checked by calorimetry. The cyclic experiments (heating-cooling) were recorded at $10 \mathrm{~K} / \mathrm{min}$ under argon atmosphere. DSC scans above room temperature were performed in the DSC 30 device of Mettler-Toledo working with a liquid nitrogen cooling system.

$\mathrm{X}$-ray diffraction (XRD) analyses were performed at room temperature with a Siemens D500 Xray powder diffractometer using $\mathrm{Cu}-\mathrm{K} \alpha$ radiation $(\lambda=1.5418 \AA)$. Scanning was carried out in the interval $30^{\circ} \leq 2 \theta \leq 75^{\circ}$ with a step increment of $0.05^{\circ}$.

\section{Results and discussion}

XRD patterns of both alloys were collected at room temperature, as shown in figures 1 and 2. The knowledge of crystal structure at room temperature determines the temperature scan. If the phase detected by XRD is cubic, the austenite-martensite transition must be found below room temperature. If the detected phase is tetragonal, orthorhombic or monoclinic, the austenitemartensite transformation must be found by heating the alloy. In this work, both alloys show a cubic L $2_{1}$ structure. This is confirmed by the existence of the peaks associated to the reflections indexed as $\left(\begin{array}{lll}1 & 1 & 1\end{array}\right),\left(\begin{array}{lll}3 & 1 & 1\end{array}\right)$ and $\left(\begin{array}{lll}3 & 3 & 1\end{array}\right)$. Miller indexes were assigned with the aid of indexing programs as Treor and Dicvol. XRD lattice parameters are given inside the graphs. As increasing indium content the lattice parameter increases slightly. It is known that Heusler alloys sometimes present texture effects, but no significant texture was here observed.

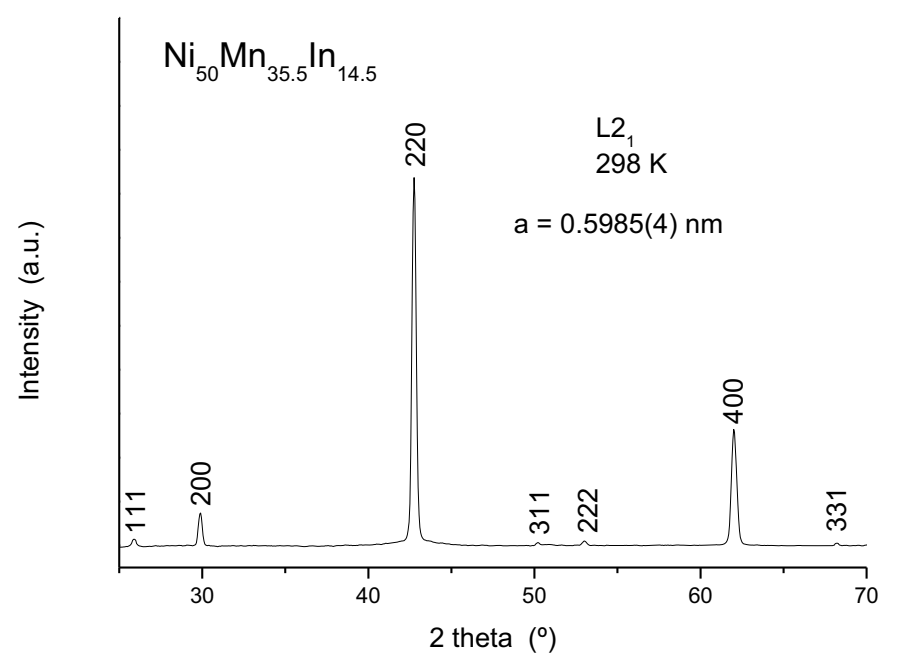

Figure 1. X-ray diffraction pattern at room temperature for $\mathrm{Mn}_{50} \mathrm{Ni}_{35.5} \mathrm{In}_{14.5}$ alloy. The crystalline structure is cubic $\mathrm{L} 2_{1}$. 


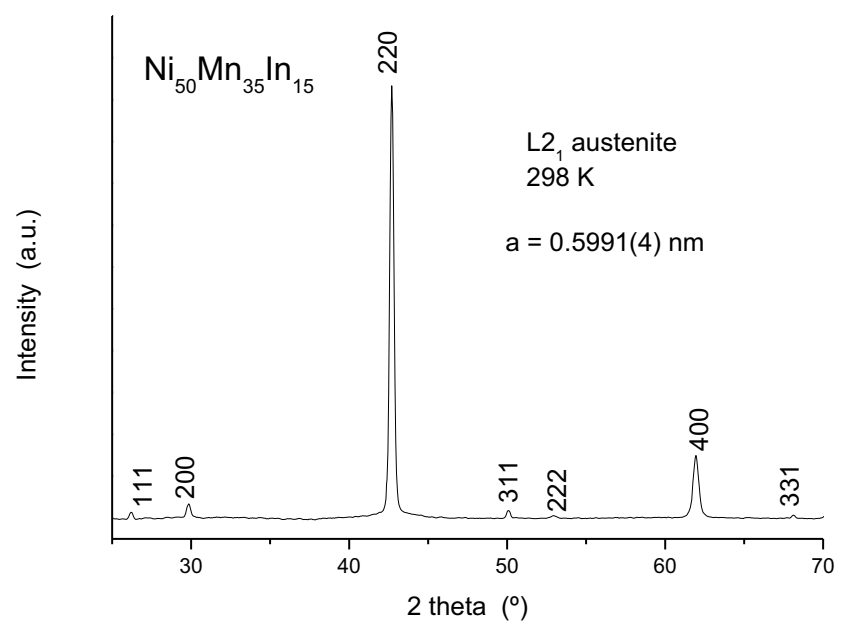

Figure 2. X-ray diffraction pattern at room temperature for $\mathrm{Mn}_{50} \mathrm{Ni}_{35} \mathrm{In}_{15}$ alloy. The crystalline structure is cubic $\mathrm{L} 2_{1}$.

From XRD analysis, DSC scans were performed under room temperature. Cyclic experiments were done due to the hysteresis of the transformation. In the alloy In14.5, the cyclic process appears near room temperature (fig.3). Nevertheless, in the In15 alloy this transition was not found. In bulk alloys, the compositions near 16 at.\% of indium are close to the limit of martensite transformation [8]. This composition can be shifted by the processing conditions and the columnar shape of the crystals obtained by melt spinning.

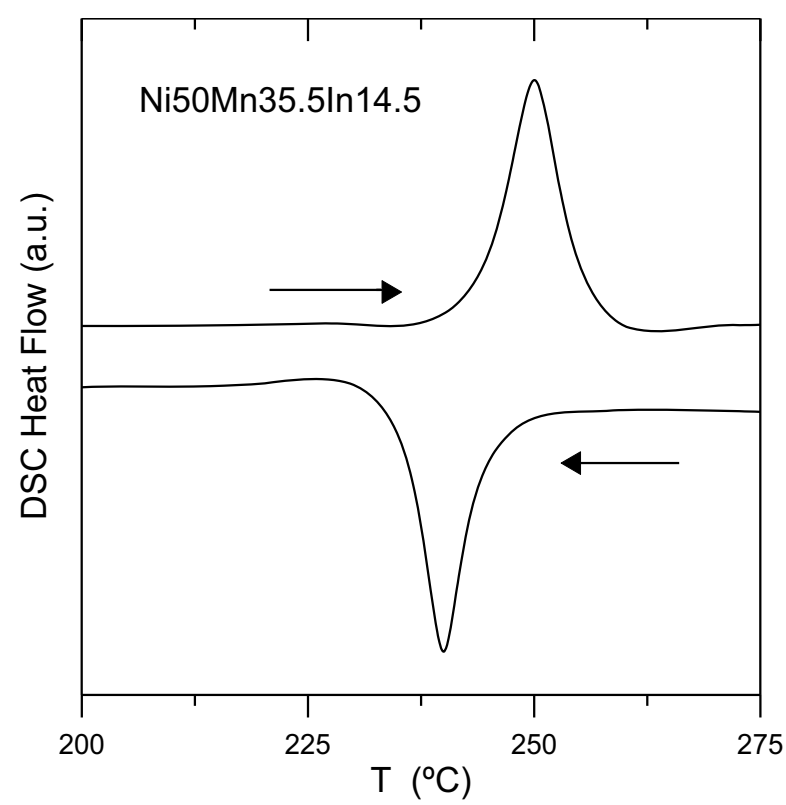

Figure 3. DSC cyclic scan for the alloy $\mathrm{Mn}_{50} \mathrm{Ni}_{14.5} \operatorname{In}_{14.5}$ at a heating/cooling rate of $10 \mathrm{~K} / \mathrm{min}$. Arrows indicate heating (up: austenite to martensite) and cooling (down: martensite to austenite).

The characteristic transformations temperatures at which martensite start and finish $\left(M_{s}\right.$ and $\left.M_{f}\right)$, and austenite start and finish $\left(A_{s}\right.$ and $\left.A_{f}\right)$ are collected in table 1 . The hysteresis is due to the increase of the elastic and the surface energy during the martensite formation. Thus, the nucleation 
of the martensite implies supercooling. For it, it is determined the width of the hysteresis, $\Delta T$, as the difference the temperatures corresponding to the peak position, $11 \mathrm{~K}$ in alloy $\mathrm{In} 14.5$. The transformation region can be also characterized by the martensite transformation temperature $T_{0}$ (the temperature at which the Gibbs energies of the martensitic and parent phases are equal [9]).

$$
T_{o}=\frac{1}{2}\left(M_{s}+A_{f}\right)
$$

In this alloy, $T_{o}$ is $242.5 \mathrm{~K}$.

Table 1. Structural transition temperatures and the associated characteristic thermal parameters: $\mathrm{h}$ and $\mathrm{c}$ indicates calculated from heating or cooling respectively

\begin{tabular}{|c|c|c|c|c|c|c|c|c|}
\hline Alloy & $M_{s} /{ }^{\circ} \mathrm{C}$ & $M_{f} /{ }^{\circ} \mathrm{C}$ & $A_{s} /{ }^{\circ} \mathrm{C}$ & $A_{f} /{ }^{\circ} \mathrm{C}$ & $\Delta T /{ }^{\circ} \mathrm{C}$ & $T_{0} /{ }^{\circ} \mathrm{C}$ & 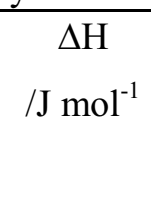 & $\begin{array}{c}\Delta \mathrm{S} \\
/ \mathrm{Jmol}^{-} \\
{ }^{1} \mathrm{~K}^{-1}\end{array}$ \\
\hline \multirow[t]{2}{*}{ In14.5 } & 247 & 229 & 238 & 258 & 11 & 242.5 & $231(\mathrm{~h})$ & $0.44(\mathrm{~h})$ \\
\hline & & & & & & & $254(\mathrm{c})$ & 0.49 (c) \\
\hline
\end{tabular}

The entropy $(\Delta S)$ and enthalpy $(\Delta H)$ changes of the structural transformations are calculated from calorimetry data $[10]$ using the relationships

$$
\Delta H=\int_{T_{i}}^{T_{t}}\left[\left(\frac{d Q}{d t}\right)\left(\frac{d T}{d t}\right)^{-1}\right] d T
$$

and

$$
\Delta S=\int_{T_{i}}^{T_{t}}\left[\frac{1}{T}\left(\frac{d Q}{d t}\right)\left(\frac{d T}{d t}\right)^{-1}\right] d T
$$

where $T_{i}$ and $T_{f}$ are the temperature limits of integration.

The entropy and enthalpy change values are also included in table 1.

XRD analysis was also performed at $160 \mathrm{~K}$. As expected, a martensite structure was found in the In14.5 alloy (fig. 4) whereas the crystalline phase of the In15 alloy is austenitic. The martensite phase is a monoclinic $10 \mathrm{M}$ with texture in the $\left(\begin{array}{lll}1 & 2 & 5\end{array}\right)$ reflection. In alloys with similar composition obtained directly by arc melting, the XRD patterns at room temperature correspond to modulated martensite structures [8]. The monoclinic structure was 10M (alloys with 15.5 and 15 at.\% In) or $14 \mathrm{M}$ (alloy with 10 at.\% In), whereas cubic austenite was found in alloys in the range between 16 and 25 at $\%$ In as shown in figure 5. Furthermore, mixed modulated and textured structures were found at room temperature in spun $\mathrm{Ni}_{50} \mathrm{Mn}_{36} \mathrm{In}_{14}$ [11]. Probably, the modification of either the production conditions or small changes in composition favours the thermal stability of different structures and, in consequence, different magneto-elastic behaviour. The small and constrained grains in the flakes might have made difficult the transition to the martensite phase and shift it to lower temperatures, probably associated with the increased degree of quenched-in short-range disorder around defects, as proposed by Chernenko et al. [12]. Obviously, factors as a slight shift in the valence electron concentrations also increase the structural complexity.

Complementary studies are in course in order to understand better the role of the variability of synthesis conditions and the effect of thermal annealing on the microstructure, phase transformation and magnetic properties. 


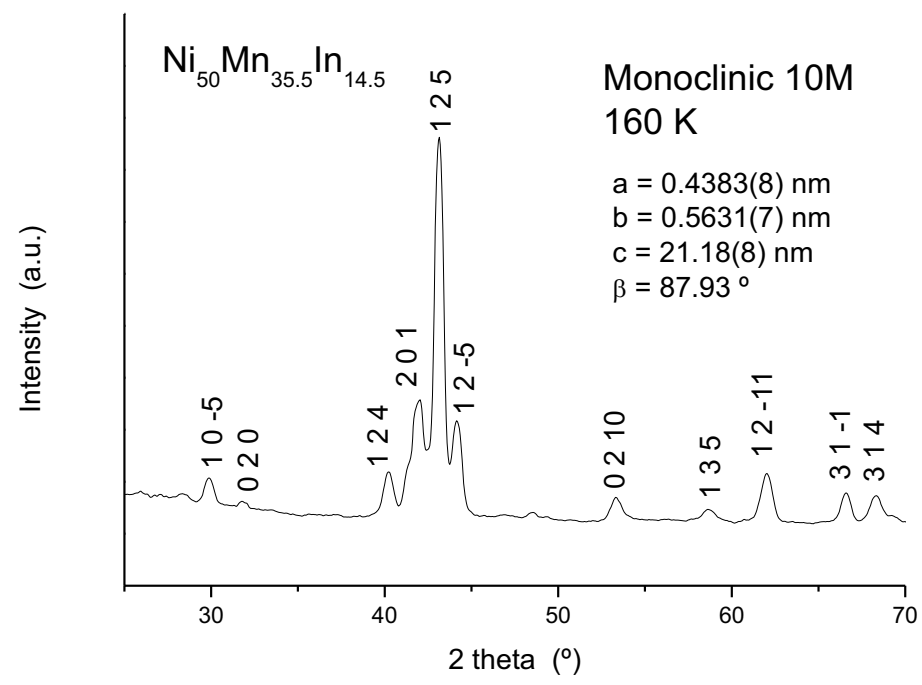

Figure 4. X-ray diffraction pattern at $160 \mathrm{~K}$ for $\mathrm{Mn}_{50} \mathrm{Ni}_{35.5} \mathrm{In}_{14.5}$ alloy. The crystalline structure is martensite monoclinic $10 \mathrm{M}$.

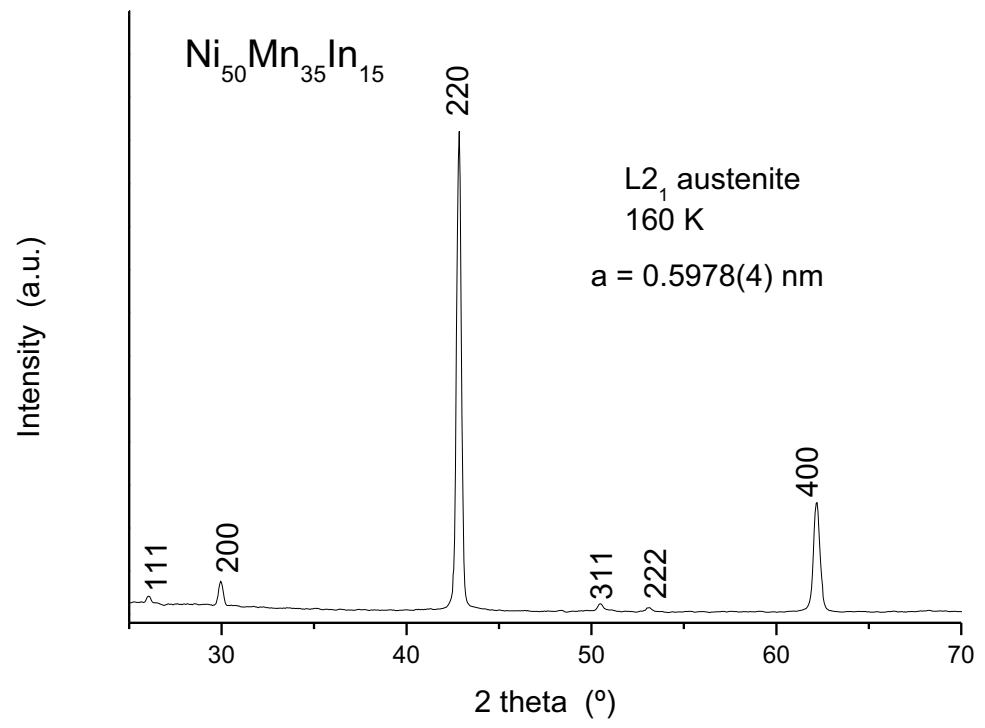

Figure 5. X-ray diffraction pattern at $160 \mathrm{~K}$ for $\mathrm{Mn}_{50} \mathrm{Ni}_{35} \mathrm{In}_{15}$ alloy. The crystalline structure is cubic $\mathrm{L} 2{ }_{1}$.

\section{Conclusions}

The austenite-martensite transformation in the Ni-Mn-In system is influenced by small changes in composition. $\mathrm{Ni}_{50} \mathrm{Mn}_{35.5} \mathrm{In}_{14.5}$ has the transformation near room temperature whereas $\mathrm{Ni}_{50} \mathrm{Mn}_{35} \mathrm{In}_{15}$ alloy has not this transformation (at least at temperatures over $160 \mathrm{~K}$ ). In the In 14.5 alloy the width of the hysteresis is $11 \mathrm{~K}$ and the martensite transformation temperature is $242.5 \mathrm{~K}$. 
Acknowledgements: Present research was carried under the supporting Spanish grants MAT200913108-C01/02 (MICINN).

\section{References}

[1] Krenke T, Duman E, Acet M, Wassermann EF, Moya X, Mañosa L, Planes A, Suard E and Ouladdiaf B 2007 Phys. Rev. B 75104414

[2] Bhobe PA, Priolkar KR and Nigam AK 2007 Appl. Phys. Lett. 91242503

[3] Pierre J, Karla L and Kaczmarska K 1999 Physica B: Cond. Matter 259-261 845

[4] Marioni MA, O'Handley ROC, Allen SM, Hall SR, Peel DJ, Richard ML, Feuchtwanger J, Peteron BW, Chambers JM and Techapiesancahoroenkij R 2005 J. Magn. Magn. Mater. 25 290

[5] Sánchez Llamazares JL, Sanchez T, Santos JD, Perez MJ, Sanchez ML, Hernando B, Escoda L, Suñol JJ and Varga R 2008 Appl. Phys. Lett. 92012513

[6] Santos JD, Sanchez T, Alvarez P, Sanchez ML, Sánchez Llamazares JL, Hernando B, Escoda L, Suñol JJ and Varga R 2008 J. Appl. Phys. $10307 \mathrm{~B} 326$

[7] Sánchez Llamazares JL, Hernando B, García C, González J, Escoda L and Suñol JJ $2009 \mathrm{~J}$. Phys. D: Appl. Phys. 42045002

[8] Krenke T, Acet M, Wassermann EF, Moya X, Mañosa L and Planes A 2006 Phys. Rev. B. 73 174413

[9] Kaufman L, Hullert M. Thermodynamics of Martensite Transformations in Martensite, Eds. Olson G.B. and Owen W.S. 1992 ASM International; 41-58

[10]Coll, R, Escoda L, Saurina J, Sánchez-Llamazares JL, Hernando B and Suñol JJ 2009 J. Therm. Anal. Calorim.,DOI 10.1007/s10973-009-0489-2

[11] Cai W, Feng Y, Sui JH, Gao ZY and Dong GF 2008 Scripta Materialia, 58830

[12] Chernenko VA, Cesari E, Pons J and Seguí C 2000 J. Mater. Res. 151496 